\author{
Elżbieta Jendrych \\ Kozminski University, Warsaw
}

\title{
DEVELOPMENTS IN ESP TEACHING
}

\begin{abstract}
The fast changing business environment and the ever-growing demand facing professional communicators in the $21^{\text {st }}$ century pose new challenges to language learners and teachers alike. Competitive business organizations attempt to recruit employees who have excellent linguistic competence coupled with nonlinguistic competences and skills. It is not easy to acquire these additional competences and skills. However, most of them are transferable and can be greatly improved if students are provided with adequate teaching materials and appropriate input from the teacher. The aim of the paper is to address the complexity of ESP teaching today. Firstly, it presents an overview of the changes that have occurred in the practice of teaching ESP in the last few decades. It also sheds some light on the increasing importance of needs analysis. Then it presents new developments in teaching English for professional communication at the tertiary level of education. These developments include (1) content-and-language integrated learning, (2) use of didactic case studies, (3) corpus studies conducted for teaching purposes and aimed at identifying high-frequency language elements: terms, specialized lexis items, collocations, formulae, acronyms, etc., that need to be prioritized in language courses, (4) more effective course-books with higher terminology indexes, (5) extended use of online materials, (6) teaching writing for specialized purposes, and (7) teaching cross-cultural and social skills. The new approach is more challenging for ESP teachers and requires much higher qualifications, such as content knowledge and transferable skills. In order to increase students' employability and promotion opportunities, we need teaching materials and approaches that help streamline students' efforts, economize on time, and increase the effectiveness of language courses.
\end{abstract}

Keywords: English for Specific Purposes, business English, needs analysis, teaching priorities, materials development

Teaching English for Specific Purposes (ESP) is a prime illustration of the saying "what comes in time, changes over time." ESP as a term came into language more than 50 years ago. The notion of a language for specific job-related purposes appeared in the sixties and the early seventies of the $20^{\text {th }}$ century and was connected with the pioneering research of Halliday, MacIntosh and Strevens (1964). Since its introduction ESP has been changing and developing all the time, and it is expected to change and develop in the future as well. 


\section{Elżbieta Jendrych}

Widdowson (1983:10) is of the opinion that "ESP is simply a matter of describing a particular area of language and then using this description as a course specification to impart to learners the necessary restricted competence with this particular area." Hutchinson and Waters (1987:19) support the idea that ESP must be seen as an approach, rather than a product.

According to Hutchinson and Waters (1987:5), there were three main reasons for the emergence of all varieties of ESP: the demands of the New World after WW II, a revolution in linguistics, and a focus shift from the teacher to the learner (Hutchinson \& Waters, 1987; Dudley-Evans \& St. Johns, 1998). English became subject to the wants, needs, and demands of people other than language teachers. It was the learner who explicitly called for courses tailored to meet their professional needs.

A significant discovery at that time was that the ways in which we speak a language and write in a language vary. The significance of this discovery was that, as a result of these variations in language use, language teaching could be tailored to both spoken and written professional situations. In the late 1960s and the early 1970s, there were first attempts to teach English for Science and Technology (EST). It was the first variety of language for specific purposes that received scientific attention. Hutchinson and Waters (1987), Swales (1980), and Selinker and Tarone (1981) were among the EST pioneers.

Another significant discovery came from the psychology of learning the research showed that another focus shift was needed, that from language delivery to language acquisition (Hutchinson \& Waters, 1987). Focus on learners' needs became as important as the methodology of language teaching. Designing courses that could best meet these needs was bound to be a success.

According to the definition given by Hutchinson and Waters (1987:19), "ESP is an approach to language teaching in which all decisions as to content and method are based on the learner's reason for learning." It was a real revolution in language teaching - from a teacher-centered approach to a learner-centered and learning-centered approach, a milestone in language teaching that had its repercussions for the decades to come.

In 1983, Carter distinguished three varieties of ESP: English as a restricted language, English for Academic and Occupational Purposes, and English with specific topics. The famous "tree of ELP" (Hutchinson \& Waters, 1987) shows that ESP was subdivided into English for Science and Technology (EST), English for Business and Economics (EBE), and English for Social Studies (ESS). Each of these three varieties was further 
subdivided into EAP and EOP. Now ESP is an umbrella term which includes English for Science and Technology, English for Academic Purposes, English for Business and Economics, English for Management, English for Medicine, English for Finance and Banking, English for Law, English for Tourism/Engineering/Accounting, etc.

The number of ESP dictionaries reflects the creation and development of each variety of ESP. By analyzing the year of publication, the type and the number of ESP dictionaries on the market, we can make conclusions on the popularity of each ESP variety. In the 1980s and 1990s, about 80 new ESP dictionaries (mostly technical) appeared on the Polish market, and during the period 1990-2006 there were more than a hundred new business dictionaries available in Poland. It demonstrates the popularity and expansion of ESP.

Today we can witness that publishers not only offer course-books and on-line materials for the varieties of ESP presented above but also publish books and materials targeted at a single profession, e.g. English for Nurses, English for Job Hunters, English for Beauticians or Air Speak (English for Air Traffic Controllers). The variety of course-books on offer shows that there is a huge demand for highly specialized language courses.

At the early stages of ESP teaching, courses were aimed mainly at specialized linguistic competence. In the 1970s, specialized terminology and functional language were regarded to be the priorities in ESP courses. Courses were, to a great extent, language-oriented, and their main aim was to teach specialized lexis and grammar. In the mid-1970s and 1980s, a new approach to teaching business English appeared - it was the communicative language teaching approach focused on communication in typical professional situations. With time the priority of linguistic competence was replaced by the priority of communicative competence, and communication skills became target number one in ESP.

In Europe, the 1990s were the decade when the following important innovations were introduced: the euro, financial deregulation, and venture capital. Throughout the world, globalization processes brought greater job mobility and international cooperation. It was also the time when new communication technologies became more accessible worldwide: the Internet and mobile phones have significantly facilitated and sped up communication. All these changes have had a strong impact on learners' needs.

Successful ESP courses imply that course-book authors cater for future real-life needs of learners, especially in the case of pre-experienced adult students, who may not fully realize what language competence their future job will require of them. Target situations, in which they will have to com- 


\section{Elżbieta Jendrych}

municate effectively, have to be examined (as part of needs analysis) and considered when designing a course-book.

A learner-centered approach adapted in ESP courses has allowed for the following developments in language teaching:

- inclusion of materials into a syllabus is based on the learners' reasons for learning,

- courses are more intensive - learners want to achieve good language competence in the shortest time possible,

- learners can negotiate the syllabus,

- learning is understood as an active construction of meaning,

- teaching is perceived as guiding, scaffolding, and facilitating learning,

- real-life tasks are prioritized,

- meaningful and purposeful interaction can be created through language,

- tasks are cognitively more challenging,

- learners have more autonomy,

- learners accept more responsibility for the outcome of the learning process,

- making vocabulary personal helps to make it more memorable (McCarten, 2007).

Today we can still witness that demand for English for Specific Purposes continues to increase and expand throughout the world (DudleyEvans, 2001). Learners need courses matching their ever growing needs and requirements resulting from what the labour market demands.

The aim of the next sections of the paper is to address the complexity of ESP teaching today. Firstly, it presents recent developments in teaching English to pre-experienced adult students at the tertiary level of education which include (1) content-and-language integrated learning, (2) use of didactic case studies, (3) corpus studies conducted for teaching purposes and aimed at identifying high frequency language elements: terms, specialized lexis items, collocations, phrases, formulae, acronyms, etc., that need to be prioritized in language courses, (4) more effective course-books with higher terminology indexes, (5) extended use of online materials, (6) teaching writing for specific purposes, and (7) teaching professional culture and non-linguistic skills. Then it focuses on new challenges that ESP teachers face, and, finally, it offers some practical recommendations for ESP teachers. 


\section{Recent Developments in ESP}

In this section the information will generally refer to all ESP varieties, but examples will refer mostly to business English teaching.

\section{Content-and-language Integrated Learning (CLIL)}

Content-and-language integrated learning was introduced in ESP at the end of the $20^{\text {th }}$ century. It has been advocated by the Language Division of the Council of Europe in all types of formal education: primary, secondary, and tertiary (Language Division 2004). In their report Council of Europe experts strongly support CLIL courses run at universities. They also advocate materials development for specific groups of students to facilitate CLIL.

The classical model of CLIL requires two teachers: a language teacher and a subject matter teacher. In practice, however, the dominant teaching model at universities now is that with one teacher who teaches both subject matter and language.

It can be expected that this type of learning will become more popular in the future. More and more universities all over the world look for and welcome students from abroad - from neighboring countries or from emerging economies - countries like China or India. The only way to give education to these students is in the medium of English, which is taught in most secondary schools all over the world. Some experts say that we are facing the "Englishization" of tertiary education. It could be a unique opportunity to provide international students with intensive CLIL courses in ESP.

The priorities in CLIL comprise professional communication skills combined with practicing active language skills. CLIL offers teaching that is targeted at content matter, but strong emphasis is also put on using academic, professional, and authentic course materials with high terminology input.

There are four types of knowledge presented by Anderson and Krathwohl (2001):

- factual knowledge - basic facts, components, terminology,

- conceptual knowledge - knowledge of classification, rules, theories, models, and processes,

- procedural knowledge - ability to perform specific tasks and to solve problems,

- meta-cognitive knowledge - understanding learning strategies, understanding the importance of life-long learning.

In CLIL we have more opportunities to teach conceptual, procedural, and meta-cognitive type of knowledge which are more difficult to teach 


\section{Elżbieta Jendrych}

than factual knowledge. This makes teaching ESP at tertiary level more meaningful and effective.

For language teachers CLIL can frequently be very difficult. As language teachers they may not want to learn the content matter. It has to be remembered that the direct and indirect costs of postgraduate or doctoral studies (in terms of time and money) are usually high. In addition, there may be negative attitudes to teaching content matter and no trust in the value of CLIL. As a result of these difficulties, constraints, and negative attitudes, language teachers refrain from accepting teaching positions in CLIL courses. Consequently, universities look for content matter teachers with good linguistic competence. Then, however, the primary focus is on content matter, and ESP is given a secondary focus only.

\section{Use of Didactic Case Studies}

A learner-centered approach provides students with lots of opportunities to practice analytical and creative thinking, problem solving, and decision making. It teaches critical and constructive thinking, evaluation and forecasting and thus contributes to the development of conceptual thinking. A learner-centered approach encourages students to defend their ideas and to reflect on their thinking when they take decisions, critically compare, and evaluate options or design an action plan. It also allows them to compromise and reach a consensus when they work in teams. The use of didactic case studies in tertiary education is a prime example of a learner-centered approach.

The case study method is used extensively in law, medicine, psychology, economics, management, and in finance. It is also used in some varieties of ESP. A didactic case presents a real life problem that either has been solved or needs to be solved. It gives some background information to the problem. It often contains some data in the form of graphs, documents, interviews, tables, etc. that may be helpful in identifying the problem and in solving it.

Language skills which can be practiced in the case study method include:

- reading skills with exposure to new vocabulary in various professional areas,

- speaking skills such as:

presenting opinions,

criticizing,

negotiating,

making a point, 
comparing alternatives,

taking a decision and justifying the choice,

presenting conclusions,

- writing skills.

There are many advantages of the case study method. First of all, most students like realistic real-life tasks. Cases require team work and cooperation and can be adjusted to the level of language competence in a particular group of learners. Teachers have numerous opportunities to supplement a case with new tasks, both spoken and written. Additionally and importantly, students know that they use the language they will need most in real-life professional situations.

The didactic qualities of case studies include the following:

- language is a tool to perform a real-life task,

- the method allows to practice all language skills with emphasis on the productive skills of speaking and writing which are most difficult to master,

- it offers 'learning by doing',

- it is student-centered,

- speaking is more spontaneous,

- student speaking time is prolonged,

- language is practiced in a natural way (language is the means, not an end).

Frendo (2007:13) is of the opinion that in teaching business English, like in the world of business language, it is not the end, it is the means to achieve the end. He says,

in the business English classroom this is often done via tasks, which are activities where the focus is primarily on using language to do something. It is the outcome of the task which is important, just as in the business world the language is a means to the end, not an end in itself. The theory is that that language is learned via the interaction; the learners learn by doing the task. Many researchers claim that task-based learning, coupled with judicious feedback which allows learners to pay more attention to form, is the most productive way of using a language.

Case studies may be challenging not only for the student but also for the teacher. They require professional thinking, knowledge of certain rules and mechanisms, as well as excellent analytical skills. Sometimes the methodology of analyzing more complex cases may be difficult or time-consuming. It, however, should not lead to eliminating case studies from ESP teaching practice, especially in teaching English for Medicine, Law, and Business; 


\section{Elżbieta Jendrych}

in these content areas case studies have been used for decades in tertiary education, and they can be equally effective in teaching ESP.

\section{Use of Corpus Evidence in Materials Development}

The two quotations presented below show the importance of terminology and specialized lexis in ESP teaching. Thornbury (2002:14) is of the opinion that "the advent of the communicative approach in the 1970s set the stage for a major re-think of the role of vocabulary." Frendo (2007:8) in How to Teach Business English says that "one of the key influences on business English teaching in recent years has been our deepening understanding of the role of lexis." Teaching materials used in ESP courses should reflect the language used by professionals in typical communication acts. The content of any ESP course today needs to be judiciously selected both in terms of content matter and material selection. It is true that publishers offer much better ESP course-books now; ten or twenty years ago some ESP areas were not provided with course-books at all or the choice was limited to two or three course-books. However, course-book authors do not consider extremely important corpus evidence concerning language use.

Thornbury (2002:35) says that "the relative frequency of a word is a key factor in determining its inclusion in a syllabus. The argument for teaching the most frequent words in the language is a powerful one. It is claimed that the most frequent words express the most frequent meanings in the language."

Why do we need corpus studies? High-frequency language elements: core vocabulary (both ESP terms and specialized lexical items), area specific collocations, phrases, formulaic sequences, abbreviations and acronyms used in the language of professional communication need to be identified in corpus studies carried out for teaching purposes. Frequency lists should be a prerequisite for authors of ESP course-books. Intuition and experience of course-book writers cannot provide the hard evidence that is accessible by means of corpus studies into authentic spoken and written texts.

Students need to be exposed to the highest-frequency ESP language elements very early in the course. It will give them a sense of achievement and improve their motivation. The didactic value of a course prioritizing such elements will increase significantly. Learning time will be better used. Learning efforts will be more focused. Consequently, the effectiveness of ESP courses is likely to increase.

\section{Monitoring Specialized Terminology Indexes in Teaching Materials}

ESP terminology is the most important single factor that makes a quantum of difference between general English and English for Specific Purposes. 
Highest frequency ESP terms are of key importance in professional communication. K. Wartburton (2005), responsible for IBM's terminology strategy, says, "Terminology is the DNA of knowledge." Proper understanding and use of professional terminology allow for effective communication between specialists.

However, in tertiary teaching we need to look at terminology use from a wider perspective. Input materials have to be assessed by means of two criteria:

- the quality of ESP terms contained in teaching materials (understood as corpus-based information on which ESP terms to include),

- the quantity of ESP terms understood as their concentration in teaching materials.

A terminology index (Lukszyn, 2008) is a research tool which allows to measure the concentration of ESP terms and collocations in a text, a collection of texts or a course-book. It is measured by the ratio of ESP terms and collocations to the total number of running words in a given text or a collection of texts. This tool:

- provides unbiased quantitative data on language use in teaching materials,

- measures the didactic value of an ESP text,

- helps to assess teaching materials in terms of how much new core ESP terminology (and specific lexis) students can learn using a given text,

- shows the repetition rate of key ESP terms,

- identifies texts that require supplementation,

- assures high quality of teaching materials.

The use of the terminology index allows to measure the concentration of core ESP language elements and grade it according to students' language competence and to students' needs. It also allows for controlling the number of newly introduced specialized language elements and for monitoring their repetition rate (recycling). If the repetition rate of a given term or collocation is high, students have a more intensive input and are more likely to memorize the term.

For example, the terminology index in authentic business texts amounts to 0.25 (Lukszyn, 2008), which means that every fourth word in a text is a business term. The terminology index may vary slightly depending on the genre, subject matter, the intended reader, and the author. Effective teaching materials for tertiary students need to have a relatively high terminology index, close to that found in authentic ESP texts.

Most probably terminology indexes for other varieties of ESP differ from that in business English texts, and they may probably be either higher 


\section{Elżbieta Jendrych}

(e.g. in authentic language of chemistry, medicine or law) or lower (e.g. in the language of history, management, pedagogy or sociology) than that for authentic business texts.

In practical terms, it is quite easy to measure the terminology index for a particular course-book. It is enough to take several 100-word long samples of texts from the course-book and to count the terminology indexes in them. If the consolidated terminology index in those samples is close to 0.25 (for business texts), it can be interpreted as high enough. Course-books with a high terminology index usually do not require any supplementation.

Additionally, when analyzing the samples, it is possible to measure the concentration of specialized collocations in them. Collocations are as important in specialized communication as specialized terms. Thus, a high concentration of specialized collocations, because of its high didactic input, makes the text more effective.

\section{Extended Use of Online Materials and E-courses}

Many ESP teachers encourage their students to make use of online materials as supplementary teaching texts. It is a good practice as it gives learners an opportunity to have greater exposure to authentic specialized texts. Students usually like to use online materials (area specific texts, documentaries, case studies, articles in quality professional journals, company websites, video clips, etc.) and think that such materials add variety to the learning process.

The popularity of e-courses is increasing and will probably continue to increase in the future. Most e-courses that are currently offered to learners are in general language, not in ESP. However, there are a few courses in business English, and in the future courses in other ESP varieties are likely to become available as well. Learners like them since they offer greater flexibility than regular language classes. They also give an immediate feedback to the learner.

Recently, a new generation business English course-books have been introduced on the market. Besides a student's book, teacher's book, workbook, and skills book, publishers sell these books with an additional elearning component for students. Teachers can manage the teaching materials and monitor each student's performance in e-component tasks. This kind of blended learning offers more intensive exposure to business English - the e-component allows for 30-40 additional hours of language learning.

Massive Open Online Courses (MOOCs) are a completely new type of online courses run by the best and most renowned universities worldwide and offered for free to all learners wanting to enroll. For instance, Coursera 
- an online system of free training - offers specialized courses in law, management, finance, and economics as well as in sociology, history, medical sciences, and mathematics taught by university professors from such reputable universities as Stanford, Harvard or the London School of Economics. Up to now more than six million people worldwide have already enrolled in these courses. Many of them also take language courses offered by Coursera; for the time being these are courses in general languages only.

The popularity of MOOCs shows that there is a huge demand for online learning; in the future this demand is likely to increase. Most probably online ESP courses will be offered to mass learners in the years to come. The practical lesson for ESP practitioners at universities is to be aware of the changes, to make attempts to incorporate online materials in ESP courses, and also to consider developing online courses and online supplementary materials for adult learners of ESP.

\section{Teaching Writing for Specific Purposes}

In the recent decade we have seen that more and more ESP courses have offered a component of professional writing. It refers particularly to the language of business and law as these ESP varieties require that professionals have particularly good writing skills. There are texts and documents they have to produce in a professional and standardized way.

Professional writing has been incorporated into language courses to meet the needs of students who will need to be effective, informative, and persuasive communicators in writing. Each of the following groups of professionals needs instruction in specialized forms of writing: managers, management consultants, and business people as well as lawyers. The writing code in each of these professions is different, even though they have certain elements in common.

In the world of business these forms of writing include business reports, memoranda, corporate profiles, trade contracts, commercial correspondence, business plans, annual reports, advertisements, agendas, itineraries, minutes, press releases, among others. Each of the forms of writing listed here has a special layout, structure, style, and tone. It requires a specialized routine language, brevity of form, and clarity of argumentation. It also requires a specific degree of formality and appropriate wording. University students certainly need to learn how to write for professional purposes.

Teaching writing is a difficult task for two basic reasons: (1) secondary school students generally do not know how to write in a logical, clear, brief, and structured way, neither do they know how to write in an informative or persuasive way, and (2) teaching writing for professional purposes is time- 


\section{Elżbieta Jendrych}

consuming and needs a lot of planning, organizing, drafting, and redrafting. With a limited number of classes in ESP courses at universities it is often difficult to provide students with enough opportunities for acquiring good writing skills.

If students want to take external certificate qualifications (e.g. English for Business LCCI or BEC), it is necessary to teach them to produce business texts required for the exam. The growing popularity of certificate exams seems to indicate that more and more students want to have written confirmation of their competence in a given ESP awarded to them by an external examination board. An increasing number of corporations require such language certificates from their employees and from job applicants.

\section{Teaching Sociolinguistic and Pragmatic Competence}

The last (but not least) development in ESP teaching refers to teaching non-linguistic skills. Good communication skills require excellent language skills matched with good pragmatic and sociolinguistic skills. Many of these skills are transferable and can be learned. Professionals usually need good interpersonal skills, business and managerial skills, analytical skills, persuasion skills as well as specific micro-skills.

In business these micro-skills are extremely important and can have farreaching consequences for professional performance; thanks to those skills you can generate profits for your company and contribute to its development and growth. They include such micro-skills as e.g. negotiating, networking, chairing a meeting and participating in one, delivering business presentations, giving a sales pitch, attending customers, presenting facts and figures, using visuals, networking, and telephoning.

Harmer (2003:10) says that

an enormous growth area in English language teaching has been in the area of Business English because many students perceive a need for the kind of language which will allow them to operate in the world of English-medium commerce. Once again there is specific vocabulary and language events (presenting to colleagues, the language of contracts, etc.) which are unlikely to appear in a general English course, but which are vitally important for business students. And so teachers find themselves training classes in such procedures as the art of negotiating, the correct use of phones and e-mail, or the reading of business reports.

In our globalized world, good interpersonal skills also encompass crosscultural skills. Professionals are likely to have contacts with other professionals as well as customers and clients from different cultures. Awareness of cultural differences makes cross-cultural contacts significantly easier and 
beneficial for all parties involved. Accepting that we are culturally diverse and respecting things that are culturally important for others help in developing and maintaining good professional contacts with foreigners. Crosscultural skills help to avoid potentially dangerous cultural clashes or misunderstandings, which may have negative consequences.

The knowledge of the basic principles of professional etiquette also plays a significant role. Students who know the rules of etiquette, good manners, and rituals prevailing in their future profession will probably find it easier to adapt to the code of good practices that are respected in their profession. Even very small details can work to students' advantage, e.g. how to promptly reply to letters or emails, how to address people or what dress code to follow.

Some universities teach professional skills in separate courses. They give courses in negotiations or in business culture. If, however, this is not the case, ESP teachers have to consider teaching those skills during language classes, time permitting. There are some ESP course-books that are accompanied by skills books and cross-cultural components. The decision of what to include in the course depends on numerous criteria, with the number of teaching hours being the strongest determinant of what a syllabus can realistically include.

It is important to remember, as McGrath (2002:98) says, that

knowledge and skill combine in efficient communication. However, teaching for knowledge is very different from teaching for skill. Knowledge can be 'presented' or 'discovered'; it can also be forgotten. Skill, on the other hand, can only be acquired through practice, and once acquired is relatively easily maintained. The fact is that while we can 'teach' knowledge, we cannot teach skill. Skill has to be learned, and practice is a central element in that learning.

\section{The Challenges ESP Teachers Face Today}

The first and most essential piece of information that can be offered to novice ESP teachers is that they will have to learn many new things they were not taught during their university years. And they will have to continue learning throughout their professional life. As simple as that. As demanding as that. The bar for qualified ESP teaching is going higher and higher.

The idea that ESP is a general language plus specialized vocabulary, advocated by some laymen, has already been rejected. University teachers who think that in ESP teaching they are not responsible for transferring area specific knowledge are in a slim minority now. Teachers have to understand the meaning of specialized terms, they have to know and understand 


\section{Elżbieta Jendrych}

the basic facts, mechanisms and processes they discuss with their students, and they have to have some rudimentary knowledge in the subject matter they teach.

In order to increase the effectiveness of the courses they teach, ESP teachers are expected to learn many new things that will help them make their teaching better and more effective. These include learning:

- how to respond to learners' needs,

- how to teach non-linguistic skills (pragmatic and sociolinguistic skills),

- what to prioritize in an ESP course (high-frequency lists),

- how to select and incorporate authentic materials into the course,

- how to evaluate teaching materials using quantitative methods,

- how to make use of online materials and social networks,

- what new teaching techniques to implement (e.g. case studies),

- how to teach for ESP certificate exams,

- how to teach effective writing for professional purposes.

ESP teachers need to put a lot of time and energy into being better performers in what they do professionally. It can be achieved by either self-education, by collaborating with and learning from subject matter specialists, by taking postgraduate courses offered to novice ESP teachers or by enrolling for doctoral studies either in ESP or in the subject matter.

Witnessing so many developments in ESP teaching, it can be assumed that the potential for growth is huge. ESP teachers who will follow these developments and who will be open to possible challenges in the future are likely to succeed. Teachers need to change and develop - changes lead to improvements in the quality of ESP teaching. Changes should not be avoided; change resistant teachers find it difficult to adapt to the changing needs of their students, to develop, and improve as ESP teachers.

\section{Conclusions and Discussion}

For more than 50 years of ESP courses learners' needs have always been most relevant and central in the practice of ESP teaching. Over time these needs have become more complex. Today's labour market does not resemble that of the 1980s or 1990s. Today employers demand more from their employees than they used to. Therefore, tertiary students who want to meet these demands have to invest more time, money, and energy to achieve good language competence.

In the opinion of Richards (2006:1), the worldwide demand for English has created an enormous demand for quality language teaching and lan- 
guage teaching materials and resources. He claims that learners set themselves demanding goals and that "they want to be able to master English to a high level of accuracy and fluency." He adds, "employers, too, insist that their employees have good English language skills, and fluency in English is a prerequisite for success and advancement in many fields of employment in today's world." This new demand is a consequence of several processes that have occurred in those 50 years: globalization of the labour market, higher employee mobility, increased competition, expansion of big multinational organizations, extensive use of cheap labour, off-shoring, closer crossborder cooperation, progress in communications and information technology, greater access to university education, and growing unemployment, to name just a few most significant ones.

ESP teachers have to be aware of all the developments presented in this paper. They need to remember that universities seek to employ only the best ESP teachers. Their employability is bound to increase if their qualifications in ESP teaching are constantly upgraded. Generally speaking, specialization in language teaching is inevitable. Consequently, investment in professional life-long learning and development translates into more employment opportunities. Novice ESP teachers are strongly recommended to make the effort and learn the fundamentals of the subject matter relevant to the ESP variety they want to teach. It is important to remember that such rudimentary knowledge is always beneficial when teaching ESP to adult students.

Looking back 50 years, it can be said that tremendous progress has been made in all aspects of ESP teaching. All the developments presented in the paper support this view and demonstrate that the effectiveness of ESP courses has improved significantly over time. ESP course-books are more interesting for learners, they offer real-life tasks and contain many authentic texts. Frequently they are accompanied by workbooks and skills books. On the one hand, it makes teaching easier for the teacher, but on the other, it poses new challenges and threats that the teacher has to face.

It can be concluded that all elements of the teaching/learning process (the learner, the teacher, and teaching materials) have changed and developed over the last 50 years and that great progress has been made in ESP teaching. The effectiveness of ESP courses has increased significantly; consequently, the level of language competence and communicative competence among professionals has risen.

Still, there are some areas for further improvement: ESP varieties still require intensive corpus studies for teaching purposes, the didactic relevance 


\section{Elżbieta Jendrych}

of teaching materials has to be monitored and upgraded, and technology has to be widely used in ESP teaching practice. Research in psycholinguistics and neurolinguistics can shed some new light on the learning process as well. It is to be hoped that more new developments are likely to come for ESP in the future.

\section{R E F E R E N C E S}

Anderson, L. W. \& Krathwohl, D. R. (2001). A Taxonomy for Language Learning, Teaching and Assessment. New York: Longman.

Carter, D. (1983). Some propositions about ESP. The ESP Journal, 2, 131-137.

Dudley-Evans, T. \& St. Johns, M. (1998). Developments in ESP: A MultiDisciplinary Approach. Cambridge: CUP.

Frendo, E. (2007). How to Teach Business English. Harlow: Longman.

Halliday, L. W., MacIntosh, A. \& Strevens, P. (1964). The Linguistic Sciences and Language Teaching. London: Longman.

Harmer, J. (2003). The Practice of English Language Teaching. Harlow: Longman.

Hutchinson, T. \& Waters, A. (1987). English for Specific Purposes: A Learningcentered Approach. Cambridge: CUP.

Language Policy Division. (2006). Experts' Report: Poland. Council of Europe: Strasbourg.

Lukszyn, J. (2008). Parametry analizy tekstów specjalistycznych. In J. Lukszyn (Ed.), Podstawy technolingwistyki (pp. 182-196). Warszawa: KJS UW.

McCarten, J. (2007). Teaching Vocabulary. Lessons from the Corpus, Lessons for the Classroom. Cambridge: CUP.

Richards, J. (2006). Communicative Language Teaching Today. Cambridge: CUP.

Selinker, L., Tarone, E. \& Hanzeli, V. (1981). English for Academic and Technical Purposes: Studies in Honour of Louis Trimble. M.A.: Newbury House.

Swales, J. (1980). ESP: The Textbook Problem. The ESP Journal, 1 (1), 11-23.

Thornbury, S. (2002). How to Teach Vocabulary. Harlow: Longman.

Wartburton, K. (2005). Terminology: Getting Down to Business. Retrieved from: www.translationdirectory.com/article526.htm.

Widdowson, H. (1983). Learning Purpose and Language Use. Oxford: OUP. 